\title{
Aortic valve sclerosis is a sign of increased arterial stiffness in clinically asymptomatic subjects
}

\author{
Levent Korkmaz, Mustafa Tarık Ağaç, Huseyin Bektas, Mustafa Oguz Varol, \\ Hakan Erkan, Zeydin Acar, Devrim Kurt, Şükrü Çelik
}

Department of Cardiology, Ahi Evren Cardiovascular and Thoracic Surgery Training and Research Hospital, Trabzon, Turkey

\begin{abstract}
Background: Classic risk scores may underestimate the risk of cardiovascular (CV) events in specific risk groups requiring appropriate medical and interventional treatment. Arterial stiffness has been known as a sign of $C V$ risk and has a predictive value for $C V$ events beyond classic $C V$ risk factors. The purpose of this study was to investigate the relation between the cardio-ankle vascular index (CAVI) that has been recently reported as a new surrogate marker of arterial stiffness and aortic valve sclerosis (AVS).
\end{abstract}

Methods: Eighty patients with AVS and 80 control subjects were enrolled to the study. Arterial stiffness was evaluated by VaSera-1000 CAVI instrument and AVS was defined by echocardiography as thickening and calcification of the normal trileaflet aortic valve without obstruction to the left ventricular outflow.

Results: CAVI was significantly higher in patients with AVS compared to the control subjects (10.5 \pm 2.7 vs. $8.6 \pm 1.4, p<0.001)$. Higher frequency of AVS was detected in patients with abnormal than borderline and normal CAVI values (69\% vs. $27 \%$ and $20 \%$, respectively, $p<0.001)$. In univariate analysis, there was a significant association between AVS and CAVI (95\% confidence interval [CI] 1.44-2.48, $p<0.001]$. Multivariate analysis demonstrated CAVI (95\% CI 1.39-2.44, $p<0.001)$ as an independent determinant of AVS.

Conclusions: Detection of increased arterial stiffness could prevent patients from being mistakenly classified as at low or moderate risk, when they actually are at high risk. Assessment of aortic valve during echocardiography examination may offer the opportunity to identify these subjects. (Cardiol J 2013; 20, 3: 318-322)

Key words: aortic valve sclerosis, arterial stiffness, cardio-ankle vascular index

\section{Introduction}

Aortic valve sclerosis (AVS) is defined by echocardiography as thickening and calcification of the normal trileaflet aortic valve without obstruction to the left ventricular outflow. The prevalence of AVS has been estimated at the level of $25-30 \%$ in patients $\geq 65$ years and up to $40 \%$ in those $\geq 75$ years $[1,2]$. Several reports have demonstrated a significant association between AVS and atherosclerosis risk factors or clinical atherosclerosis [3-5].

Arterial stiffness is a non-traditional cardiovascular $(\mathrm{CV})$ risk factor and increasing evidence has implied that arterial stiffness is a marker of all

Address for correspondence: Levent Korkmaz, MD, Department of Cardiology, Ahi Evren Cardiovascular and Thoracic Surgery Training and Research Hospital, Trabzon, Turkey, tel: +90 462 2314114, fax: +90 4622312420 ,

e-mail:1.korkmaz@yahoo.com

Received: 22.10.2012 Accepted: 14.12.2012 
cause and CV mortality, fatal and non-fatal coronary events $[6,7]$. The cardio-ankle vascular index (CAVI) has been recently reported as a new index of arterial stiffness [8]. There is little known about association between AVS and arterial stiffness [9]. The main purpose of this study was to investigate this relation by using CAVI as a marker of arterial stiffness, which is less influenced by blood pressure than pulse wave velocity (PWV) [10].

\section{Methods}

\section{Subjects}

Eighty subjects with AVS and age-gender and traditional CV risk factors, and 80 subjects without AVS were prospectively selected from the subjects directed to the echocardiography laboratory at the Ahi Evren Thoracic And Cardiovascular Surgery Training And Research Hospital. Patients with aortic stenosis (transaortic flow velocity $>2.5 \mathrm{~m} / \mathrm{s}$ ), rheumatic valvular disease prosthetic valves, bicuspid aortic valves, congenital heart disease, bacterial endocarditis, atrial fibrillation, or hypertrophic obstructive cardiomyopathy, as well as those who had suffered from symptomatic vascular disease such as stroke, transient ischemia, coronary heart disease, congestive heart failure symptoms or ejection fraction less than $50 \%$, and intermittent claudication or any peripheral artery revascularization, were excluded from the study. Coronary heart disease was defined by: (1) self reported myocardial infarction, angina, or use of nitroglycerin; and (2) self-reported history of coronary angioplasty or coronary artery bypass surgery. Cerebrovascular disease was defined by self-reported stroke, transient ischemic attack, or carotid endarterectomy. AVS is defined by echocardiography as thickening and calcification of the normal trileaflet aortic valve without obstruction to the left ventricular outflow. CAVI measurement and echocardiograhic examination were performed by 2 different investigators who were blinded to the patients clinical data (AOV and $\mathrm{HB}$, respectively). Informed consent was obtained from all subjects.

\section{Assessment of cardiovascular risk factors}

In addition to questions about the symptoms of ischemic heart disease, peripheral vascular disease, and stroke, data on the CV risk factors, diabetes mellitus, arterial hypertension, and smoking habits were obtained. Patients were considered to be hypertensive if they had a systolic blood pressure $>140 \mathrm{~mm} \mathrm{Hg}$ and/or diastolic pressure $>90 \mathrm{~mm} \mathrm{Hg}$ or were using antihypertensive drugs.
Subjects with fasting glucose $\geq 126 \mathrm{mg} / \mathrm{dL}$ and/or use of pharmacological treatment were considered diabetics. Smoking was defined as "current smokers" or "nonsmokers". Hypercholesterolemia was defined as total cholesterol $>200 \mathrm{mg} / \mathrm{dL}$ or taking medications.

\section{Arterial stiffness measurements}

Arterial stiffness was assessed by CAVI. It was measured using a VaSera VS-1000 CAVI instrument (Fukuda Denshi Co. Ltd., Tokyo) by the methods described previously [10]. CAVI was measured in the morning after $12 \mathrm{~h}$ of fasting within 1 day after echocardiography. Briefly, cuffs were applied to the bilateral upper arms and ankles, with the subject supine and the head held in the midline position. After resting for $10 \mathrm{~min}$, measurements were performed. Electrography, phonocardiography, and pressures and waveforms of brachial and ankle arteries were measured. Next, CAVI were automatically calculated. According to the manufacturer company recommendations, CAVI was considered normal $(\mathrm{CAVI}<8)$, borderline $(8 \leq \mathrm{CAVI}<9)$ and abnormal (CAVI $\geq 9$ ) [11].

\section{Statistical analysis}

Continuous variables were expressed as mean \pm standard deviation (SD) and categorical variables were expressed in percentages. The analysis of normality of the continuous variables was performed with the Kolmogorov-Smirnov test. The comparison of the categorical variables between the groups was performed using a $\chi^{2}$ test. Continuous variables were compared using unpaired t-test and Mann-Whitney U test. Binary logistic regression analysis was performed for all parameters to determine the association between AVS and all variables. Variables with $\mathrm{p}$ value $\leq 0.1$ were selected for multiple logistic regression analysis. Multiple logistic regression analyses were carried out to detect independent predictors of AVS. A p value of $<0.05$ was considered statistically significant. Statistical analysis was conducted by using SPSS 14.0 statistical software.

\section{Results}

Clinical, demographic and laboratory characteristics of patients and control subjects were illustrated in Table 1 . There was statistically significant difference of CAVI values among AVS and control subjects (Fig. 1). In univariate analysis, there was significant association between AVS and CAVI (95\% confidence interval [CI] 1.44-2.48, 
Table 1. Clinical, demographic and laboratory characteristics of patients and control subjects.

\begin{tabular}{lccc}
\hline & No AVS (n = 80) & AVS (n = 80) & P \\
\hline Age [years] & $71 \pm 7$ & $73 \pm 6$ & 0.09 \\
Male gender & $28(35 \%)$ & $33(41 \%)$ & 0.41 \\
Hypertension & $65(81 \%)$ & $71(88 \%)$ & 0.08 \\
Diabetes & $13(16 \%)$ & $11(13 \%)$ & 0.71 \\
Smoking & $11(11 \%)$ & $13(16 \%)$ & 0.23 \\
Dyslipidemia & $19(24 \%)$ & $21(26 \%)$ & 0.64 \\
Body mass index $\left[\mathrm{kg} / \mathrm{m}^{2}\right]$ & $31 \pm 5$ & $29 \pm 4$ & 0.09 \\
LDL-C $[\mathrm{mg} / \mathrm{dL}]$ & $139 \pm 37$ & $137 \pm 38$ & 0.81 \\
HDL-C [mg/dL] & $47 \pm 12$ & $43 \pm 13$ & 0.25 \\
Triglyceride $[\mathrm{mg} / \mathrm{dL}]$ & $148 \pm 68$ & $149 \pm 69$ & 0.97 \\
Cholesterol $[\mathrm{mg} / \mathrm{dL}]$ & $208 \pm 44$ & $205 \pm 51$ & 0.83 \\
Cardiovascular medication & & & 0.07 \\
ACE-I or ARB & $37(47 \%)$ & $48(60 \%)$ & 0.46 \\
Calcium channel blockers & $22(27 \%)$ & $26(32 \%)$ & 0.09 \\
Beta-blocker & $10(13 \%)$ & $18(22 \%)$ & 0.55 \\
Cholesterol-lowering drugs & $18(22 \%)$ & $21(26 \%)$ & 0.04 \\
ASA & $15(19 \%)$ & $26(32 \%)$ & $<0.001$ \\
CAVI & $8.6 \pm 1.4$ & $10.5 \pm 2.7$ & \\
\hline
\end{tabular}

ACE-I - angiotensin converting enzyme inhibitors; ASA - acetylsalicylic acid; AVS - aortic valve sclerosis; ARB - angiotensin receptor blocker; CAVI — cardio-ankle vascular index; HDL-C — high-density lipoprotein cholesterol; LDL-C — low-density lipoprotein cholesterol

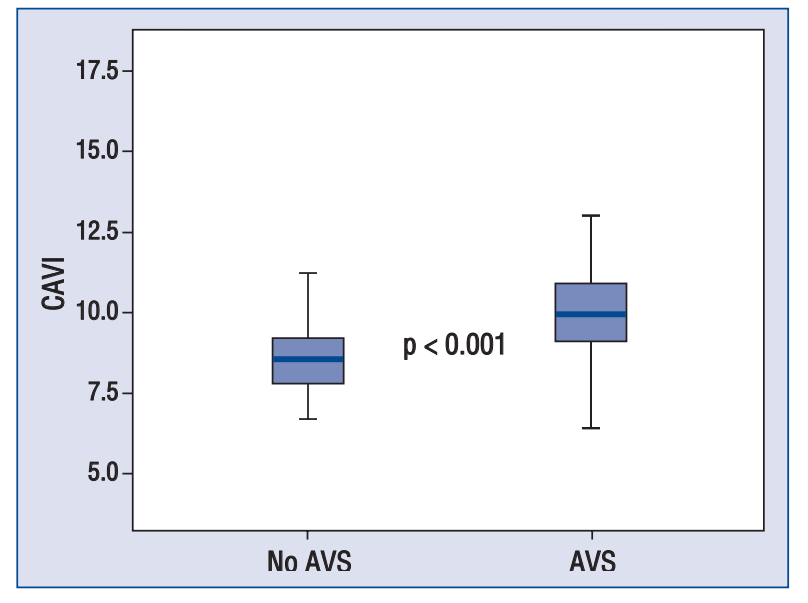

Figure 1. Cardio-ankle vascular index (CAVI) was increased in aortic valve sclerosis (AVS) patients, compared to the control subjects.

$\mathrm{p}<0.001)$. Multivariate analysis demonstrated CAVI (95\% CI 1.39-2.44, $\mathrm{p}<0.001)$ as an independent determinant of AVS (Table 2).

We also examined the frequency of AVS in normal, borderline and abnormal CAVI categories. Number of patients with normal, borderline and abnormal CAVI values were 30, 37 and 93, respectively. We found higher frequency of AVS in patients with abnormal CAVI values than borderli- ne and normal ( $69 \%$ vs. $27 \%$ and $20 \%$, respectively, $\mathrm{p}<0.001$ ) (Fig. 2).

\section{Discussion}

In present study, we have found increased CAVI values representing arterial stiffness in asymptomatic subjects who had AVS. Also, there was a significant and independent association between presence of AVS and CAVI.

Arterial stiffness has been known as a sign of $\mathrm{CV}$ risk for a long time, and assessment of arterial stiffness improved the prediction of $\mathrm{CV}$ disease when added to traditionally recognized CV risk factors [12]. Several mechanisms may explain the association between arterial stiffness and coronary heart disease. Arterial stiffness has a negative hemodynamic effect on heart by causing increase of systolic and decrease of diastolic blood pressure. These changes lead to the increase in myocardial oxygen demand, reduce in ejection fraction, increase in ventricular load and inducing left ventricular hypertrophy [13]. Decrease of diastolic blood pressure can compromise coronary perfusion, resulting in subendocardial ischemia [14]. Furthermore, stiffer arteries may contribute to rupture and ulceration of atherosclerotic plaques [15], especially when inhomogeneity in stiffness in and around the plaque is present [16]. In addition, 
Table 2. Univariate and multivariate analysis of aortic valve sclerosis and variables.

\begin{tabular}{lccccc}
\hline & \multicolumn{2}{c}{ Univariate analysis } & & \multicolumn{2}{c}{ Multivariate analysis } \\
\cline { 2 - 3 } \cline { 5 - 6 } & $\mathbf{P}$ & $\begin{array}{c}95 \% \text { confidence } \\
\text { interval }\end{array}$ & & $\mathbf{P}$ & $\begin{array}{c}\text { 95\% confidence } \\
\text { interval }\end{array}$ \\
\hline Cardio-ankle vascular index & $<0.001$ & $1.44-2.48$ & & 0.001 & $1.39-2.44$ \\
Hypertension & 0.08 & $0.16-1.12$ & & 0.07 & $0.11-1.09$ \\
Diabetes & 0.71 & $0.49-2.83$ & & - & - \\
Dyslipidemia & 0.65 & $0.41-1.73$ & & - & - \\
Smoking & 0.04 & $1.07-14.76$ & & 0.069 & - \\
Male gender & 0.42 & $0.41-1.46$ & & - & $0.91-15.6$ \\
Age & 0.09 & $0.91-1.21$ & & 0.35 & -1.09 \\
\hline
\end{tabular}

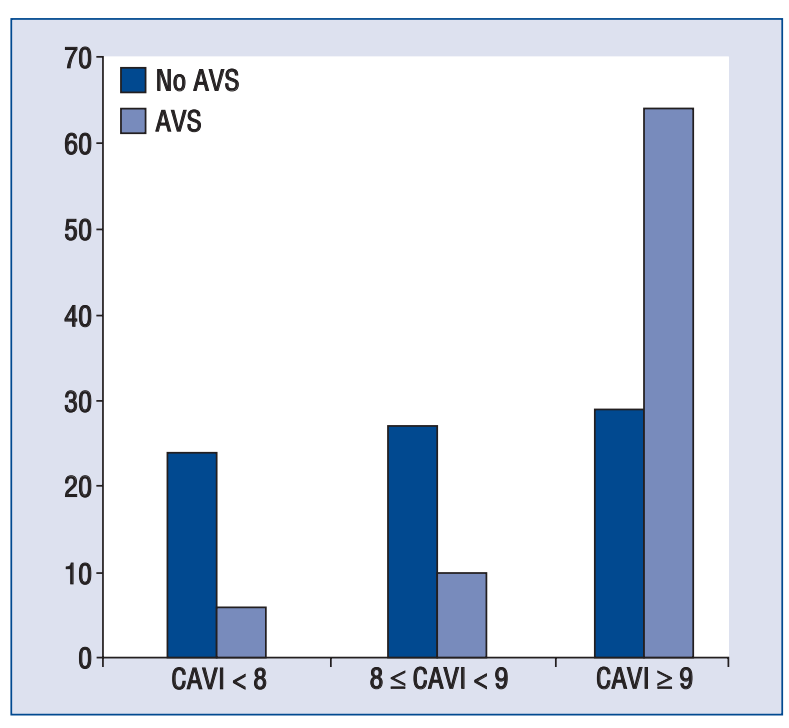

Figure 2. Frequency of aortic valve sclerosis in different cut off value of cardio-ankle vascular index (CAVI).

increased pulse pressure that is a consequence of arterial stiffness is independently associated with arterial plaque ulceration and rupture [17].

The presence of AVS has been suggested as a marker of increased CV risk, including increased mortality. Also, after adjusting for baseline characteristics, AVS was associated with increased risk of $\mathrm{CV}$ death, including higher rates of myocardial infarction and congestive heart failure among patients without prior history of coronary artery disease [18]. Moreover, in a recently published study, AVS predicts all — cause and CV mortality [19]. Therefore, AVS may be considered a potentially useful prognostic factor in patients without overt evidence of coronary artery disease [20,21].

Relation between AVS and arterial stiffness may be explained by the fact that AVS represents a surrogate marker either for underlying atherosclerotic disease $[3,22]$ or some generalized systemic process, such as inflammation [23, 24]. Furthermore, similarities of valve composition in aortic valve sclerosis to atherosclerotic disease give credence to the biologic plausibility of the association of aortic valve sclerosis with both traditional clinical risk factors and CV events. Arterial stiffness provides information about the functional and structural vascular changes and surrogate marker of atherosclerosis. It has been related to the Framingham and other CV risk scores.

In the previous study, we did not find a meaningful relation between AVS and arterial stiffness, assessed by carotid-femoral PWV [9]. In present study, we evaluated arterial stiffness by CAVI on which blood pressure has less impact. In addition, Cecelja et al. [25] performed a systematic review of cross-sectional published literature in order to determine independent predictors of arterial stiffness assessed by carotid - femoral PWV. They found consistent independent association between PWV and age and blood pressure. But no independent association between PWV and sex, total cholesterol, low-density lipoprotein cholesterol, high-density lipoprotein cholesterol, triglycerides, smoking, or body mass index were noted. Therefore, they reached to the conclusion that the contribution of risk factors other than age and blood pressure to PWV is small or insignificant. Thus, the discrepancy in results of 2 studies may be due to methodological issues inherent in the evaluation of arterial stiffness by different techniques.

\section{Limitations of the study}

There are limitations to our study. First of all, number of study population is relatively small. Based on its cross sectional study, the present findings are inherently limited to explain causal 
relationship between AVS and CAVI. Also, we have excluded subjects with ankle brachial index $<0.9$ since CAVI in these subjects may be inaccurate.

\section{Conclusions}

In conclusion, we have demonstrated AVS as a marker of increased arterial stiffness in subjects who were asypmtomatic and clinically free of $\mathrm{CV}$ disease. Echocardiographic examination of aortic valve may have a role in screening asymptomatic subjects with increased risk of CV disease in general population.

\section{Conflict of interest: none declared}

\section{References}

1. Stewart BF, Siscovick D, Lind BK et al. Clinical factors associated with calcific aortic valve disease. Cardiovascular Health Study. J Am Coll Cardiol, 1997; 29: 630-634.

2. Lindroos M, Kupari M, Heikkila J, Tilvis R. Prevalence of aortic valve abnormalities in the elderly: An echocardiographic study of a random population sample. J Am Coll Cardiol, 1993; 21: 1220-1225.

3. Agmon Y, Khandheria BK, Meissner I et al. Aortic valve sclerosis and aortic atherosclerosis: Different manifestations of the same disease? Insights from a populationbased study. J Am Coll Cardiol, 2001; 38: 827-834.

4. Pohle K, Maffert R, Ropers D et al. Progression of aortic valve calcification: association with coronary atherosclerosis and cardiovascular risk factors. Circulation, 2001; 104: 1927-1932.

5. Adler Y, Levinger U, Koren A et al. Relation of nonobstructive aortic valve calcium to carotid arterial atherosclerosis. Am J Cardiol, 2000; 86: 1102-1105.

6. Boutouyrie P, Tropeano AI, Asmar R et al. Aortic stiffness is an independent predictor of primary coronary events in hypertensive patients: A longitudinal study. Hypertension, 2002; 39: 10-15.

7. Blacher J, Guerin AP, Pannier B et al. Impact of aortic stiffness on survival in end-stage renal disease. Circulation, 1999; 99: 2434-2439.

8. Takaki A, Ogawa H, Wakeyama T et al. Cardio-ankle vascular index is a new noninvasive parameter of arterial stiffness. Circ J, 2007; 71: 1710-1414.

9. Celik S, Durmuş I, Korkmaz L et al. Aortic pulse wave velocity in subjects with aortic valve sclerosis. Echocardiography, 2008; 25: 1112-1116.
10. Takaki A, Ogawa H, Wakeyama T et al. Cardio-ankle vascular index is superior to brachial-ankle pulse wave velocity as an index of arterial stiffness. Hypertens Res, 2008; 31: 1347-1355.

11. VaSera VS-1000 operation manual, Fukuhada Denshi CO.,LTD, Tokyo, Japan. Availableat:URL:http://www.fukuda.co.jp/english/ products/special_features/vasera/cavi.html.

12. Westerhof N, O'Rourke MF. Haemodynamic basis for the development of left ventricular failure in systolic hypertension and for its logical therapy. J Hypertens, 1995; 13: 943-952.

13. Watanabe H, Ohtsuka S, Kakihana M, Sugishita Y. Coronary circulation in dogs with an experimental decrease in aortic compliance. J Am Coll Cardiol, 1993; 21: 1497-1506.

14. Cheng GC, Loree HM, Kamm RD, Fishbein MC, Lee RT. Distribution of circumferential stress in ruptured and stable atherosclerotic lesions: A structural analysis with histopathological correlation. Circulation, 1993; 87: 1179-1187.

15. Lee RT, Kamm RD. Vascular mechanics for the cardiologist. J Am Coll Cardiol, 1994; 23: 1289-1295.

16. Lovett JK, Howard SC, Rothwell PM. Pulse pressure is independently associated with carotid plaque ulceration. J Hypertens, 2003; 21: 1669-1676.

17. Shirai K, Hiruta N, Song M et al. Cardio-ankle vascular index (CAVI) as a novel indicator of arterial stiffness: Theory, evidence and perspectives. J Atheroscler Thromb, 2011; 18: 924-938.

18. Otto CM, Lind BK, Kitzman DW, Gersh BJ, Siscovick DS. Association of aortic-valve sclerosis with cardiovascular mortality and morbidity in the elderly. N Engl J Med, 1999; 341: 142-147.

19. Volzke H, Haring R, Lorbeer R et al. Heart valve sclerosis predicts all-cause and cardiovascular mortality. Atherosclerosis, 2010; 209: 606-610.

20. Otto CM. Why is aortic sclerosis associated with adverse clinical outcomes? J Am Coll Cardiol, 2004; 43: 176-178.

21. Carabello BA. Aortic sclerosis: A window to the coronary arteries? N Engl J Med, 1999; 341: 193-195.

22. Chandra HR, Goldstein JA, Choudhary N et al. Adverse outcome in aortic sclerosis is associated with coronary artery disease and inflammation. J Am Coll Cardiol, 2004; 43: 169-175.

23. Novaro GM, Aronow HD, Mayer-Sabik E, Griffin BP. Plasma homocysteine and calcific aortic valve disease. Heart, 2004; 90: 802-803.

24. Gharacholou SM, Karon BL, Shub C, Pellikka PA. Aortic valve sclerosis and clinical outcomes: Moving toward a definition. Am J Med, 2011; 124: 103-110.

25. Cecelja M, Chowienczyk P. Dissociation of aortic pulse wave velocity with risk factors for cardiovascular disease other than hypertension: A systematic review. Hypertension, 2009; 54: 1328-1336. 